\title{
USOS E DESAFIOS DA MULTIMODALIDADE NO ENSINO DE LÍNGUAS
}

\author{
Angélica Prediger ${ }^{1}$ \\ Dorotea Frank Kersch ${ }^{2}$
}

\section{RESUMO}

Modos de produzir sentido por meio da escrita e da leitura sofrem mudanças ao longo do tempo porque novos elementos de composição e novas formas de organizar e expor o texto surgem, o que acaba ampliando o conceito de texto e de escrita. Com o acesso cada vez mais facilitado à tecnologia, os alunos chegam à escola fazendo já um bom uso da multimodalidade, quando desafiados a produzir textos. Neste artigo, discute-se o uso da multimodalidade por alunos de uma $5^{\mathrm{a}}$ série de uma escola pública de uma pequena cidade da serra gaúcha, e mostra-se a necessidade de o professor estar preparado para receber essa clientela e oferecer atividades que os desenvolvam, uma vez que cabe à escola ensinar seus alunos a ler e escrever textos dos mais variados gêneros. Os usos que as crianças já fazem da multimodalidade levam-nos a repensar o que significa ensinar ler e produzir textos na contemporaneidade.

Palavras-chave: Multimodalidade. Gênero. Produção de texto. Ensino de línguas.

\section{INTRODUÇÃO}

O presente artigo discute o papel da multimodalidade na composição de textos na sociedade cada vez mais imersa em práticas de letramento digital. Esta reflexão se justifica pela emergência de reconhecimento das potencialidades das múltiplas linguagens na composição de um texto e dos usos da multimodalidade que os alunos trazem do seu cotidiano para a aula de línguas, no caso de nosso estudo, língua portuguesa. Cabe à escola identificar e continuar fomentando as habilidades que os alunos apresentam, com a finalidade de aperfeiçoá-las e desenvolver novas habilidades de letramento digital.

Compreendendo o texto em seus aspectos multimodais, o artigo propõe, a partir de Kress (2011), Lemke (2005) e Rojo (2011), uma ampliação do conceito de escrita e da habilidade de escrever. No escopo do que vimos pensando, a escrita se torna mais do que uma produção de textos verbais escritos e passa a englobar o planejamento de estratégias que visem a articular as variadas linguagens, segundo um propósito, um objetivo comunicativo, um público-alvo e, evidentemente, o gênero 
em questão. Dondis (2007) fala de um produtor da linguagem visual como alguém que tem um papel semelhante ao de um artista ou de um arquiteto, que planeja, testa, projeta, articula, compõe, avalia. Acredita-se que o produtor de textos é, em certa medida, um artista, pois precisa projetar, testar, articular as linguagens, organizar e avaliar seu texto. Acreditamos que o aluno de hoje já faz uso de estratégias multimodais de composição do seu texto muito antes de entrar na escola, afinal de contas, na sociedade contemporânea, a vida é marcada pelo uso de várias linguagens ao mesmo tempo. Mesmo alunos que não possuem um computador em casa estão, em certo grau, imersos em práticas de leitura e escrita em espaço digital que ocorrem na comunidade onde vivem.

$\mathrm{O}$ artigo tem como principal objetivo, justamente, identificar e analisar os usos que uma comunidade de estudantes de ensino fundamental faz da multimodalidade na produção de uma entrevista de rádio. Logo, o artigo também se propõe a identificar e apresentar os desafios emergentes que essa experiência propõe ao ensino de línguas. Reconhece-se que o maior desafio é possibilitar o aperfeiçoamento das produções de textos multimodais de modo que os textos produzidos na aula de línguas reflitam aqueles textos em circulação na sociedade.

A identificação e análise dos usos da multimodalidade e dos desafios que esses usos representam para o ensino de língua materna (ou estrangeira) foi possibilitada a partir de um projeto de leitura e escrita desenvolvido com uma turma de $5^{a}$ série do Ensino Fundamental da rede pública de ensino de uma pequena cidade situada no pé da serra gaúcha. O projeto de produção de entrevista em rádio partiu de um trabalho desenvolvido em colaboração com a professora da turma, que tinha como temática a comida, uma vez que a cidade faz parte da Rota Romântica ${ }^{3}$, roteiro turístico gaúcho que tem na gastronomia um de seus pontos fortes. Os alunos tiveram a oportunidade de lançar mão de estratégias multimodais na composição de textos na aula de língua portuguesa, cujas atividades, normalmente, se concentram sobre o aperfeiçoamento da linguagem verbal escrita. Os dados foram gerados a partir da gravação das entrevistas em rádio realizadas em vídeo pelos alunos, com o uso de câmeras de aparelhos celulares. Logo, para a análise, foram selecionadas as cenas que mais trouxeram descobertas, e estas estão dispostas em forma de imagens no corpo do artigo.

$\mathrm{O}$ artigo acha-se dividido em quatro partes. Na primeira, apresenta-se uma conceituação de texto multimodal que leva à ampliação do que significa escrever na 
sociedade midiática. Discute-se o papel da escola no desenvolvimento das múltiplas linguagens já em uso pelos alunos, muito antes de eles entrarem na escola. $\mathrm{Na}$ segunda parte, apresenta-se um projeto de produção de entrevista em rádio, realizado com uma comunidade de estudantes de língua portuguesa, a partir do qual se geraram os dados. Na sequência, discutem-se os dados, com a finalidade de identificar e analisar os usos da multimodalidade e, em seguida, apresentam-se os desafios que esses usos representam para o ensino de línguas. Por fim, destacamse algumas considerações que se podem fazer a partir desse projeto.

\section{CONSIDERAÇÕES SOBRE A MULTIMODALIDADE}

Modos de produzir sentido através da escrita e da leitura sofrem mudanças ao longo do tempo porque novos elementos de composição e novas formas de organizar e expor o texto surgem o que acaba por ampliar o conceito de texto e de escrita.

O texto impresso, como o conhecemos até o século passado, era composto por elementos como as palavras, as orações, a cor preta ou azul, as linhas, o fundo branco e algumas imagens em preto e branco. A linguagem predominante era a escrita, acompanhada da linguagem visual, que ilustrava ou auxiliava o texto escrito, sendo, portanto, acessória. Para compreender esse tipo de texto, bastava compreender a gramática da linguagem escrita, o gênero ao qual o texto pertencia e percorrer o texto na ordem em que o autor o concebia. O texto impresso continuar existindo, e muitos deles, da forma como foi descrita anteriormente. Porém, com o desenvolvimento das tecnologias, surgem textos com elementos de composição variados além da escrita, o som, a imagem, as cores, as diversas sequências. $\mathrm{O}$ texto, antes organizado de forma linear, rígida, hierárquica, dá espaço a novas formas de organização e a múltiplas linguagens, em que a escrita nem sempre é central.

Em meio a um texto constituído por linguagens variadas, em que a escrita muitas vezes não é predominante, Flusser (2007) já se questionava se a escrita estaria chegando ao seu fim. Na verdade, a escrita está se ressignificando. Escrever é, na sociedade midiática, muito mais que produzir textos meramente verbais. Saber escrever, nessa sociedade, é lançar mão de estratégias multimodais de composição 
do texto. Segundo Rojo (2011), a multimodalidade não é apenas a soma de linguagens, mas a interação entre linguagens diferentes em um mesmo texto.

Segundo Kress (1998), as tecnologias contemporâneas de produção do texto tornam fácil a combinação de diferentes linguagens. Imagens podem se combinar com escrita e com som ou até se tornarem animadas. E, segundo Gomes (2011, p. 13), "tudo isso num visual diferente, que ultrapassa os limites do que chamamos de redação e entra no campo do design, da programação visual". Nessa perspectiva, Coscarelli (2012, p. 149) parece ter esse mesmo ponto de vista:

\begin{abstract}
Com esses novos textos escritos, é preciso repensar o sentido da palavra 'texto', não como um novo conceito, mas como uma ampliação desse conceito para outras instâncias comunicativas, trazendo para ela uma concepção um pouco diferente daquela que tínhamos em mente e nas teorias da Linguística. É preciso entrar na semiótica e aceitar a música, o movimento e a imagem como parte dele.
\end{abstract}

Em um mundo marcado por princípios verbais escritos de produção do texto, esse se manifesta organizado, segundo princípios imagéticos de produção. Como afirma Kress (2004), produzir textos verbais escritos foi o modo de produzir sentido dominante no passado, apesar de haver algumas imagens em preto e branco. Já os textos atuais não seguem mais a lógica de produção do texto verbal escrito, mas seguem a lógica da imagem. O autor mostra, portanto, que novas estratégias podem guiar a produção textual. O texto pode seguir estratégias de ordem visual, sonora ou até mesmo oral. Dessa forma, é possível dizer que outras imagens, e não a escrita, podem predominar num texto. Isso impacta, evidentemente, também a leitura.

Muito já se teorizou sobre o papel do leitor frente ao texto multimodal. As possibilidades de leitura se ampliaram, uma vez que ele pode definir o ponto de partida e de limite da leitura, a ordem em que vai ler, a conexão entre os textos, além de poder compartilhar na produção do texto, como um coautor. Há teóricos, como Flusser (2007) e Levy (1993), que dizem que as novas mídias da comunicação propiciam a rapidez das conexões entre os neurônios, tornando as pessoas mais inteligentes, e há aqueles, como Coscarelli (2012) e Ribeiro (2012), que dizem que os processos cognitivos realizados durante a leitura de um texto digital, que geralmente apresenta linguagens diversas em sua composição, são semelhantes aos da leitura de um texto impresso, no qual normalmente predomina a linguagem verbal escrita. Muitos estudos, como os de Coscarelli (2012), Xavier (2005) e Cafiero (2005), falam sobre a leitura dos novos textos, mas muito pouco se tem estudado a 
escrita, ou seja, o processo de produção de um texto multimodal impresso ou digital (ou mesmo oral). Alguns estudos que vêm focando a escrita são realizados por teóricos como Araújo (2012), Gomes (2011) e D’Andrea (2010). Justamente para que a leitura seja possível, é necessária, de antemão, a organização e produção de um texto.

A escolha das linguagens ocorre dentro do propósito comunicativo, dos objetivos de comunicação, do tipo de público-alvo e do gênero. Esses são fatores imprescindíveis e determinantes para as escolhas que serão feitas na produção do texto. São eles que motivam, guiam e dão sentido a qualquer escolha de composição do texto multimodal.

Há mais dois aspectos que influenciam na produção. Um deles é o campo de possibilidades da mídia em uso. As possibilidades de postagem, configuração, seleção e combinação são múltiplas, que parecem inesgotáveis, porém são limitadas. O produtor movimenta suas escolhas dentro de um campo limitado de possibilidades. Outro aspecto que contribui na produção textual é o gosto pessoal do produtor. Porém, este não deveria ser determinante na escolha das linguagens, pois nem sempre aquilo que o produtor aprecia produz o sentido desejado.

Ao fazer uso de diferentes linguagens, o produtor do texto deverá, segundo Kress (2004), conhecer suficientemente o potencial de cada linguagem na produção de sentido e saber em que medida aquela linguagem contribui com o seu objetivo de comunicação. Logo, conforme Kress (2004), o produtor deve saber lidar com essas linguagens e desenvolver técnicas de produção semiótica, e fazendo com que essas linguagens interajam de forma harmoniosa.

Uma vez compreendido o potencial de cada linguagem e sua relação com o objetivo comunicativo, cabe ao produtor organizar e articular seus textos sonoros, visuais, escritos, dispondo-os em uma sequência, de forma que produzam sentido.

Kress (1997) aponta que as principais tarefas do produtor ou criador de representações visuais na comunicação são organização (arrangement) e exposição (display) do texto. Segundo o autor, o produtor deve saber quais textos são mais salientes e quais as relações entre esses textos pertencentes a múltiplas linguagens.

A organização do texto está amplamente ligada ao sentido que o produtor quer transmitir aos seus visualizadores ou ouvintes. O produtor deverá se interrogar constantemente sobre quais textos e quais modos de organização e de exposição 
desses textos são realmente capazes de produzir um sentido efetivo em veículos como o rádio, a televisão, o computador, o livro ou a revista.

Lemke (2002) acredita que há uma interação entre as diferentes linguagens, e, portanto, vai além da ideia de multimodalidade, propondo a concepção de hipermodalidade. $\mathrm{O}$ criador do texto multimodal não apenas atenta para a inserção de textos de múltiplas linguagens. Ele, além de buscar variação de linguagens, também deve se preocupar em criar relações coerentes entre elas. Não bastam conexões entre um texto escrito e outro texto escrito. O produtor tem o desafio de criar links entre um texto escrito e um texto sonoro, entre um texto visual e um texto oral, e vice versa.

A composição de textos multimodais não é uma tarefa restrita a um grupo privilegiado de web-designers, mas amplia-se para toda a sociedade que faz uso de textos virtuais ou impressos. Compor textos multimodais pode parecer difícil e raro para indivíduos que nasceram na cultura impressa, em que predominavam os textos verbais escritos, com poucas interações com outras linguagens, mas torna-se uma tarefa totalmente natural, sem complicações para nativos digitais. Os alunos já fazem um uso de estratégias de composição do texto multimodal muito antes de entrar na escola, pois a multimodalidade está presente nos textos impressos ou virtuais do dia a dia, como em reportagens, notícias, filmes, histórias, novelas, com os quais a criança tem contato. E se é papel da escola preparar o aluno para agir no mundo, cabe a ela continuar desenvolvendo essas estratégias e buscar novas técnicas que aperfeiçoem ainda mais as produções dos alunos, através do estudo das potencialidades de cada linguagem, e não ignorá-las.

Grosso modo, os alunos sabem juntar textos de diferentes linguagens, mas poucos aprenderam a traçar conexões entre esses textos, a distribuí-los numa sequência pertinente, a dar um tratamento especial ao texto escrito, a expor os elementos de forma coerente no espaço da tela, a produzir elementos em saliência. E para piorar, ainda menos alunos, e também professores, aprenderam a se valer das potencialidades de cada linguagem para efetivamente produzir textos animados, sonoros e visuais. Essas são algumas estratégias que a escola deveria trabalhar com seus alunos, sem esquecer uma série de habilidades técnicas que também são essenciais para lidar com o computador.

Para tanto, é necessário que o professor, mesmo aquele que, na sua formação, não foi preparado para trabalhar com a multimodalidade, procure estudar 
e analisar os elementos que compõem os textos nas telas, nas revistas, nos livros, na televisão; o papel de cada linguagem num texto; o sentido que as linguagens interligadas produzem; e estimular os alunos a ler e produzir textos de gêneros em que a multimodalidade se faça presente.

Para Rojo (2011), o desenvolvimento das tecnologias da comunicação com suas práticas sociais específicas de leitura e escrita exige que a escola foque seu trabalho nessa realidade e parta dela para ensinar. A sociedade lida com textos cada vez mais semióticos, que exigem dos alunos estratégias de escrita e também de leitura que estejam de acordo com a multiplicidade de linguagens que compõem o texto: "ocorre que, se houve e se há essa mudança, as tecnologias e os textos contemporâneos, deve haver também uma mudança na maneira como a escola aborda os letramentos requeridos por essas mudanças" (ROJO, 2011, p. 99). Levando em conta esses aspectos, a pergunta organizadora do ensino de línguas é: Que práticas sociais de leitura e escrita na tela são importantes para manter, modificar ou ampliar as atuações dentro da comunidade em que os alunos se inserem? Logo, quais habilidades digitais são necessárias para possibilitar a inserção dos alunos nessas práticas de letramento digital?

Por algum motivo, a criação da imagem, do som, do vídeo, ocupa um plano secundário na educação atual. A visualização de imagens e de vídeos e a audição de gravações são possibilitadas nas escolas, mas como uma forma de consumir informações ou até mesmo para preencher um espaço, sem relação com as atividades restantes da turma, como identificamos em Kersch e Frank (2009). Pouca importância tem sido dada ao estudo e análise dos elementos composicionais do texto, às relações entre esses elementos e a sua importância na constituição da imagem, do vídeo ou da gravação sonora. Menos ainda se possibilita aos alunos a produção de textos formados por essas linguagens. O visual, assim como o sonoro, normalmente serve de suporte ou auxílio na compreensão de textos verbais escritos ou para produzir opiniões sobre assuntos variados, através da escuta de uma notícia, da audição de uma música, da visualização de um filme ou documentário, da leitura de um texto multimodal num site. Tal postura frente ao texto multimodal desconsidera toda a carga de significado que ele carrega e os processos complexos de sua criação.

Desconsiderar a imagem e o som como uma forma de comunicação tão eficaz ou talvez mais que a escrita é tirar dos alunos a possibilidade de 
desenvolverem técnicas e habilidades de produção de imagens, vídeos e gravações que se tornam tão emergentes na sociedade atual, a qual experimenta meios de comunicação múltiplos. Os alunos precisam ser preparados para o mundo em que estão vivendo e para o futuro que os espera.

Além de ensinar os alunos a ler e a escrever textos de gêneros diversos, é também tarefa da escola aprimorar a qualidade dos textos que os alunos criam, utilizando-se da multimodalidade. Para tanto, não basta apenas ensinar a empregar estratégias de criação verbal, mas é preciso ir além, e propiciar aos alunos o reconhecimento das potencialidades das diferentes linguagens e o papel de cada uma delas nos diferentes gêneros digitais ou impressos.

O presente artigo pretende justamente identificar e analisar os usos que uma turma de alunos de $5^{\mathrm{a}}$ série, na aula de língua portuguesa, faz da multimodalidade na composição de textos.

\section{CONTEXTO DE GERAÇÃO DE DADOS}

Nesta seção, caracterizamos os participantes da pesquisa e o contexto de geração dos dados. Trata-se de uma turma de $5^{\mathrm{a}}$ série do Ensino Fundamental, de uma escola da rede pública, de um pequeno município situado na região serrana do Rio Grande do Sul. Estamos trabalhando com a professora dessa turma e investigando suas práticas desde o ano de 2010, sob a forma de pesquisa colaborativa (WELLS, 2007). A escola fica na área urbana, mas a cidade guarda muitas características do meio rural: as pessoas se cumprimentam nas ruas, a maioria se conhece. Como grande parte da população é descendente de imigrantes alemães (das primeiras levas que vieram ao Brasil, no século XIX), a maioria dos alunos ainda é, em certa medida, bilíngue (podem talvez não falar, mas as interações ainda acontecem em Hunsrückisch, uma variedade desprestigiada do alemão). São 19 ao todo - 9 meninos e 10 meninas.

$\mathrm{Na}$ escola, aprendem o alemão padrão como língua estrangeira, e a professora da turma ministra aulas de português e de alemão para essa série, e alemão do $7^{\circ}$ ao $9^{\circ}$ ano. Acompanhamos as aulas durante o ano de 2011 , todas as sextas-feiras. Após a aula, sempre tínhamos a oportunidade de conversar com a professora, avaliando a aula e planejando as próximas, sempre sob a forma de projetos. 
A cidade já se deu conta de que a língua que se fala ali é um capital simbólico, que os distingue dos demais. Apesar dessa aparente consciência, a urbanização e a acessibilidade a centros maiores, garantida pelo asfalto que liga a cidade à $\mathrm{BR}$ 116, e pelos meios de comunicação, têm mudado os hábitos linguísticos e culturais. As gerações mais jovens já não falam o alemão nas suas interações, mas continuam se identificando com a cultura alemã, presente na língua, na arquitetura e na culinária, por exemplo. O tema gerador dos projetos desenvolvidos com a turma foi a culinária, a partir do qual a professora trabalhou com diferentes gêneros, tais como a receita, a narrativa ficcional e a entrevista. É no trabalho com esse último que emergiram as questões sobre as quais vamos refletir nesta pesquisa.

A professora havia trabalhado com receita após ter ouvido, com os alunos, a apresentação de uma, num programa de rádio. Paralelamente, ela pensava em fazer o resgate de algumas receitas típicas nas famílias, com os pais ou avós. Aí resolveu juntar as duas coisas: trabalhar com a receita e com a entrevista. Os alunos construíram as perguntas em conjunto e as fizeram aos mais velhos em casa. Alguns trouxeram o resultado na forma escrita (como um questionário) e houve quem as gravasse em celular. Uma das receitas que foi trazida para a sala de aula foi a de Eierschmier, uma espécie de omelete, usada pelos antigos para passar no pão, substituindo geleia ou manteiga. A professora, então, teve a ideia de ir a uma rádio com os alunos, para que pudessem participar de um programa, falar sobre esse resgate que haviam feito, e ensinar os ouvintes a fazer Eierschmier.

Ela tentou negociar essa saída com os alunos, entretanto, eles não se interessaram pelo assunto. Decidiram eles mesmos criar um programa de rádio, em que seria feita uma entrevista, justamente sobre a Eierschmier. E foram mais longe, decidiram registrar suas criações em celular, para que as pesquisadoras pudessem ver os resultados ${ }^{4}$. Esses resultados nos surpreenderam por diferentes razões: a ideia foi dos alunos; eles não tinham recursos para filmagem (apenas celulares simples); são oriundos de famílias de classe média baixa, tinham apenas criatividade e uma professora que os estimulava (seu nível de letramento digital não lhe permitia que pudesse ajudá-los, mas os estimulava).

Considerando esse contexto, vamos, na sequência, analisar alguns recortes feitos nas gravações dos alunos, mostrando a riqueza de detalhes que usaram para 
compor o seu texto, sem isso lhes ter sido ensinado, e discutindo como o professor poderiam desenvolver essas potencialidades, caso estivessem preparados.

\section{RESULTADOS E DISCUSSÃO}

Como dissemos anteriormente, a multimodalidade faz parte de nossas vidas, e o professor de línguas tem muito a ensinar (e aprender) nesse campo. Nesta seção, analisamos os usos que os alunos da turma em estudo fazem da multimodalidade na produção da entrevista de rádio e refletir sobre eles. Já mencionamos que os alunos não tiveram qualquer orientação por parte da professora. Tudo de que eles lançaram mão vem de sua vivência fora da escola, onde eles assistem televisão, jogam videogame, acessam as redes sociais (a maioria tem perfil no Orkut e Facebook), ouvem rádio, usam o celular, ou seja, a multimodalidade está presente em suas vidas, e eles, impregnados dela. Vamos para a primeira imagem.

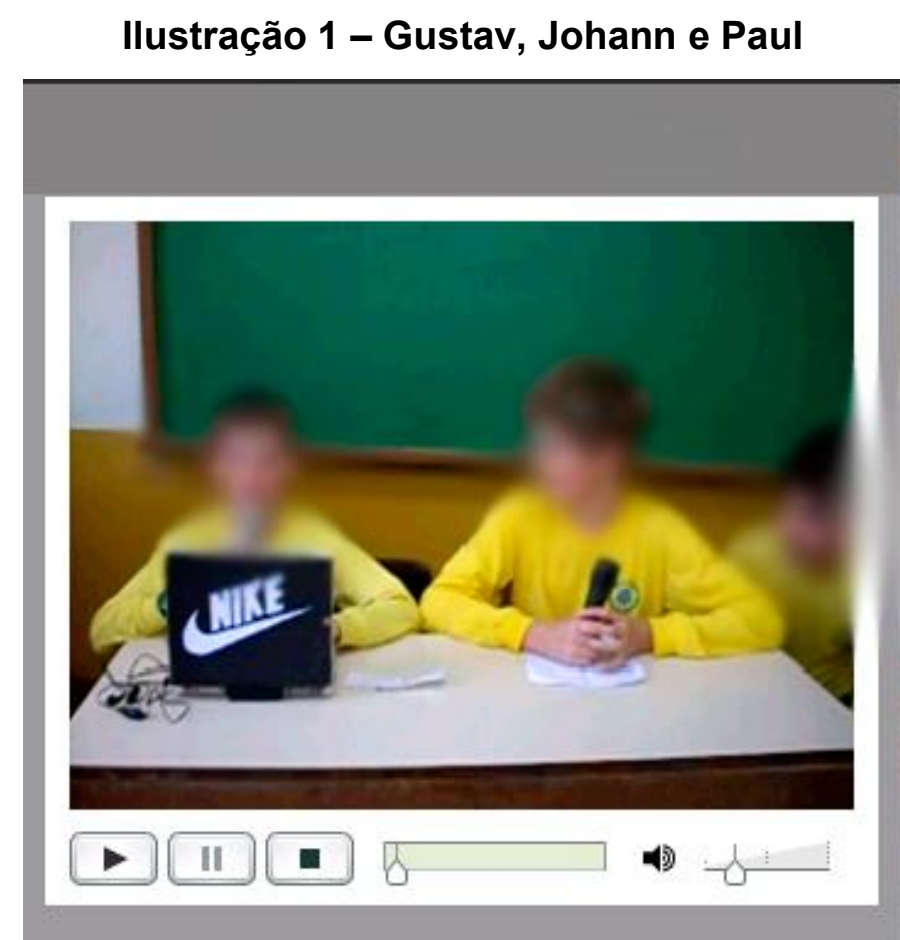

O que podemos observar no recorte são as representações de como os alunos imaginam que seja um estúdio de rádio. Verifica-se muita criatividade no uso da linguagem visual, uma vez que os produtores confeccionaram até um computador, além de apelarem para outros elementos típicos de uma emissora de 
rádio, como os microfones, as mesas, as cadeiras, o fone. Os alunos reconhecem, portanto, a eficácia que a interação de linguagens pode proporcionar na produção de sentido. Lemke (2002) destaca, justamente, que não basta a soma de linguagens, mas é preciso haver a interação do sonoro com o visual, do visual com o oral, do oral com o sonoro. Essa interação de linguagens o autor denomina de hipermodalidade. Portanto, percebe-se que os alunos já fazem uso de estratégias hipermodais. Além disso, nota-se que o locutor manteve seu olhar na direção da câmera como se estivesse falando para os telespectadores.

Nessa encenação, também se pode ouvir música no plano de fundo, durante toda a entrevista. A música toca em volume reduzido, como se já soubessem que durante a fala do locutor, o volume do som precisa ser menor para dar voz ao locutor e permitir a clara audição do ouvinte. Dessa forma, demonstraram saber colocar as linguagens oral, sonora e também a visual (o cartaz) em interação. Possibilitar a interação das linguagens significou um conhecimento prévio sobre a hipermodalidade, conforme prevê Lemke (2002). Os alunos também inseriram um intervalo comercial após a divulgação da receita para depois trazer a repetição da receita para o público que poderia não ter ouvido todos os ingredientes ou modo de preparo. Os alunos, portanto, definiram uma sequência para a programação. A repetição da receita mostrou que sabiam dos limites da linguagem sonora e que, devido à impossibilidade de visualizar a receita, o ouvinte encontraria dificuldades para anotá-la.

Vamos para a próxima imagem: 


\section{llustração 2 - Monika e Gisela}

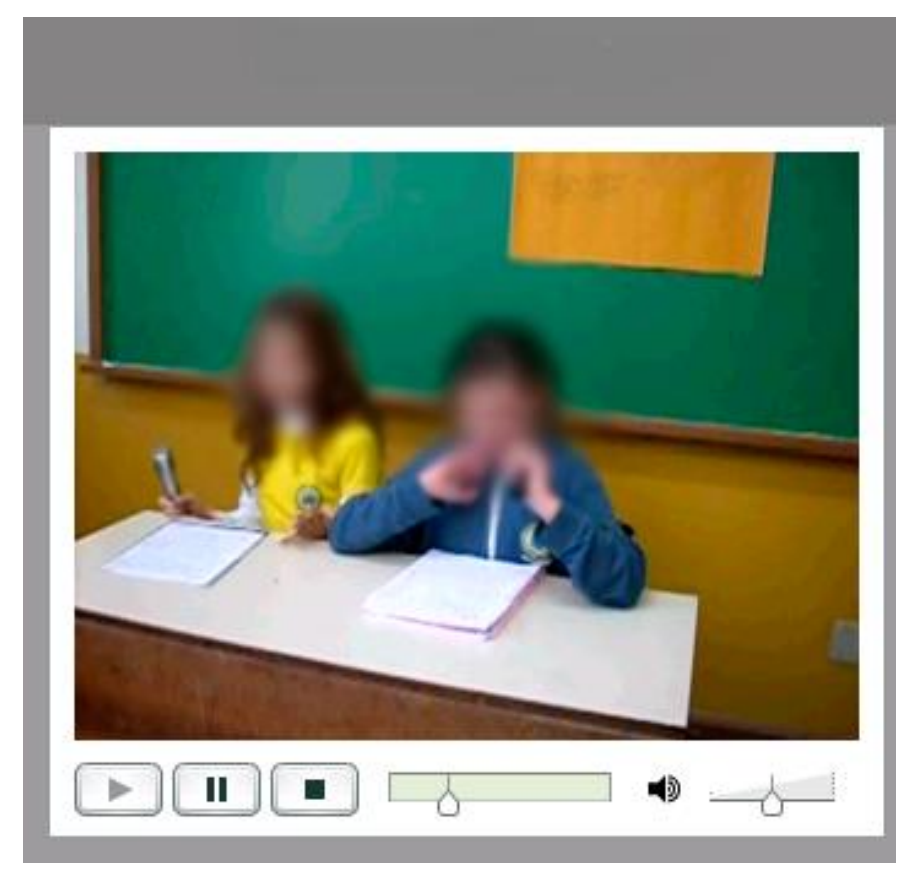

Kress (2004) diz, justamente, que o produtor do texto precisa conhecer as potencialidades de cada linguagem. $\mathrm{Na}$ cena dois, nota-se que as alunas conhecem em certa medida as potencialidades da linguagem sonora. Elas inserem música como plano de fundo para a entrevista oral. Além disso, não se trata de uma música qualquer, mas sim de uma música estilo bandinha, produzida por descendentes de alemães (semelhante com sertanejo brasileiro) que naturalmente toca na rádio dessa cidade. E, normalmente, o público que mais gosta desse tipo de música são pessoas da faixa etária acima dos 30 anos, descendentes de alemães. Assim, é possível dizer que os produtores escolheram essa música em função do público que pretendiam atingir com essa entrevista, que eram os moradores da cidade. Portanto, a escolha da linguagem sonora decorreu das características do público-alvo, manifestando um traço de sua identidade étnica.

Sigamos para a próxima imagem: 


\section{llustração 3 - Monika e Gisela}

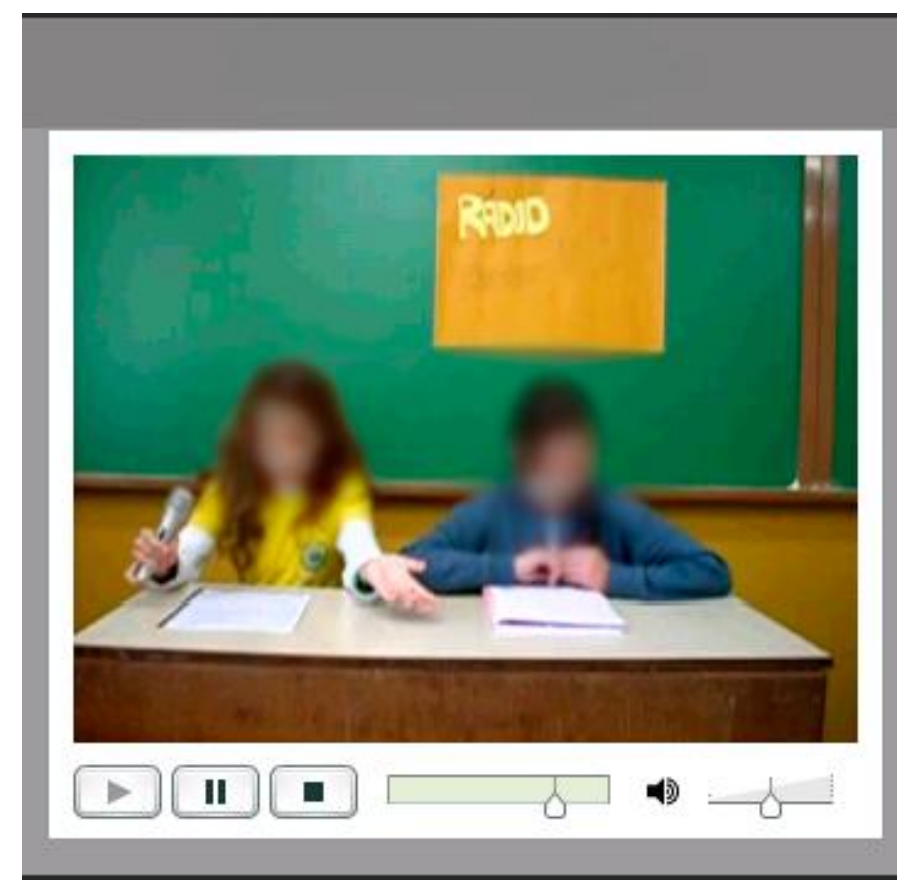

$\mathrm{Na}$ encenação, à qual a terceira imagem faz referência, é possível verificar que há um cartaz na parede, que identifica a estação de rádio e o programa. Cada grupo tenta singularizar seu 'programa de rádio' (ou pelo menos o que imaginam que seja). Assim, para identificar sua estação, usam um cartaz ao fundo. Sua ideia de estação de rádio provavelmente está ligada à ideia de uma emissora de televisão; para identificar o programa e sua estação, usam um cartaz que, na situação real, não seria visto pelos ouvintes. Esse cartaz pode parecer desnecessário em um programa via rádio, mas pode estar carregado de informação num programa via radioblog, onde os ouvintes podem, além de ouvir, também assistir. As alunas demonstram, portanto, que conhecem as potencialidades da linguagem visual na produção de sentido, o que vai ao encontro do que Kress (2004) diz em relação à tarefa do produtor: apropriar-se das potencialidades das linguagens.

Vamos para a última imagem: 


\section{llustração 4 - Petra, Hanna e Wolfgang}



Nessa produção, foi verificada a distribuição das informações numa sequência, determinada pelos produtores. $O$ momento de música, que separa a conversa sobre receita e sua divulgação, de fato, provoca a curiosidade do ouvinte e prende sua atenção. $O$ ato de inserir a linguagem sonora entre dois momentos em que predominava a linguagem oral, num momento tão esperado pelo ouvinte (que é a divulgação da receita) significou uma estratégia eficaz. Há, portanto, uma sequência na programação e os produtores se colocam no papel de artistas, como Dondis (2007) nos fala, pois selecionam, organizam e articulam as linguagens da sua produção.

É uma estratégia comum nos programas de rádio que estamos acostumados a ouvir. Quantas vezes já não ficamos ansiosos para ouvir aquela música preferida ou aquele torpedo que alguém nos mandou pelo rádio porque o locutor resolveu atrasar esse momento? Foi uma estratégia que os alunos desenvolveram por conta própria, a partir de experiências do dia a dia ouvindo rádio. Logo, se a escola reconhecer as estratégias de uso das linguagens e aproveitá-las para desenvolver novas e mais estratégias, certamente, produções mais ricas ainda surgirão.

Essa última encenação também nos permitiu observar uma adequação excelente da linguagem oral ao gênero entrevista de rádio, pois a fala é clara, objetiva, com algum grau de formalidade, como a fala da aluna à esquerda nos 
revela, quando ouvimos o áudio. Por meio da linguagem oral, ela se despede dos ouvintes de forma calorosa e amigável. A aluna, portanto, mostrou que soube adequar a linguagem ao gênero e ao público.

As produções acima analisadas também mostram que a linguagem escrita, na maior parte do tempo, guia a fala dos alunos e o andamento do programa. Mas, percebe-se, talvez até mesmo em função do gênero e do suporte, que é aberto um espaço muito maior para as linguagens sonora, oral e até visual do que para a linguagem escrita, o que vai ao encontro do que Kress (2005) diz. O autor aponta que hoje, muitas vezes, não é mais a escrita que predomina, mas outras formas de linguagem, que podem se combinar das mais variadas formas.

A análise dessas poucas imagens já nos mostra quantas possibilidades se abrem para o trabalho com gêneros em sala de aula. $E$ isso não se restringe apenas à língua materna. As potencialidades aqui elencadas poderiam ser adequadas perfeitamente também ao ensino de língua estrangeira.

No desenvolvimento de projetos de leitura e escrita, é fundamental que o professor chame a atenção para o(s) gênero(s) textual(is) usado(s), o lugar de circulação, o que prevê também para quem está produzindo. Tendo esses aspectos definidos, fica mais claro também que recursos precisam ser mobilizados, que linguagem(ns) é (são) necessária(s) para produzir o sentido que se quer produzir.

\section{CONSIDERAÇÕES FINAIS}

Os recortes das produções que colocamos em discussão aqui vão ao encontro do que Flusser (2007) pensava sobre a escrita (se ela estava desaparecendo) e mostram que, na verdade, a escrita está assumindo novas características, se ressignificando. Escrever, no projeto realizado com a turma de alunos foi aplicar estratégias multimodais de composição do texto. Escrever não se restringiu à produção de um texto verbal, mas de um texto formado por som, imagem, fala e escrita.

As produções revelaram também que os alunos já fazem uma série de usos da multimodalidade na composição de texto, souberam levar em conta o gênero (entrevista), o suporte de circulação (rádio), sem nunca terem estudado as linguagens sonora, visual e oral na produção textual de qualquer gênero. Os alunos lançaram mão de estratégias variadas de captação do ouvinte, com uso de 
elementos visuais típicos de uma rádio, uso da música e dos intervalos comerciais, de expressão corporal, de situações inusitadas para a divulgação da receita. Todas essas estratégias demonstram o conhecimento e o domínio que os alunos têm sobre as múltiplas linguagens. Além disso, levaram em conta fatores contextuais como interlocutores e veículo de comunicação, para tomar decisões quanto às linguagens a serem utilizadas e o momento de sua manifestação. Os alunos se posicionaram como artistas, pois, segundo Dondis (2007), planejaram a sua produção e procuraram compor o seu texto por meio de diferentes aplicações da multimodalidade.

Pode-se perceber que os usos que esses alunos fizeram da multimodalidade emergem da sua experiência ouvindo rádio (e assistindo à televisão) no dia a dia. Se os alunos já chegam à escola com essa série de conhecimentos acerca das linguagens em gêneros que Ihes são familiares, pode-se imaginar a riqueza das produções textuais se acaso a escola lhes ensinasse mais e novas estratégias multimodais. A escola pode proporcionar o contato direto com uma rádio da cidade, pedir que os alunos entrevistem pessoas da comunidade, apresentem alguma receita na rádio local, conversem com um locutor de rádio e até dar todo o apoio para que os alunos criem uma rádio para a comunidade escolar. Segundo Coscarelli (2012), cabe ao professor aceitar a música, a imagem e o movimento na produção textual e valorizar os usos que os alunos já fazem da multimodalidade. Logo, também é preciso reconhecer tudo o que pode ser ensinado a partir desses usos. $O$ professor pode apresentar modelos de entrevistas de rádio e possibilitar a visualização e análise desses programas, discutir adequação da linguagem, entre outras possibilidades, tanto em língua materna quanto estrangeira, já que a internet nos permite ouvir estações do mundo todo, com excelente qualidade.

Por meio de modelos de programas de rádio, pode-se fazer os alunos perceber que a linguagem sonora ocupa um espaço muito grande da locução, sendo utilizada no início, no final e diversas vezes ao longo da programação. Assim, elimina-se a linguagem sonora apenas como acessório da programação. Uma vez que se trata de uma locução para rádio, a linguagem predominante é, justamente, a sonora, permanecendo a linguagem oral como secundária, apenas para introduzir, conduzir e concluir o programa de rádio. Isso vale tanto para locuções de rádio ou de radioblog. Pode-se pensar sobre alguns cuidados importantes em relação à leitura oral ou à fala espontânea, como uma pronúncia clara, bem articulada e 
fluente, pois, gaguejos, pausas, cortes e falta de clareza podem trazer uma má impressão do locutor para o ouvinte e provocar a troca de estação de rádio ou radioblog. Tudo isso é possível mostrar aos alunos, fazendo com que eles mesmos tirem suas conclusões sobre o assunto.

A ideia de mostrar que programas podem ser gravados não só para radio, mas também para radioblog pode ser uma novidade para os alunos e valorizar ainda mais as estratégias de uso da linguagem visual. É importante destacar as possibilidades de ambos. A diferença é que no radioblog também é possível inserir a linguagem visual, por meio da gravação e postagem de um vídeo. O vídeo, em alguns casos, pode ser mais rico na produção de sentido. Diferente da locução apenas sonora, a produção de uma locução em vídeo requer uma concentração maior sobre as linguagens visual e corporal. Sendo em rádio, a preocupação é sobre a linguagem sonora.

Em se tratando de uma produção para radioblog, é necessário que se pense no sentido que se quer provocar a partir da vestimenta dos locutores, do cenário, da posição e do olhar dos locutores, dos gestos e até mesmo na forma de exposição de animações, imagens e textos verbais que possam auxiliar na divulgação da receita. Afinal, a vestimenta, do ponto de vista da linguagem visual, também comunica. Trata-se de pensar no efeito de sentido que o produtor quer causar com o tipo de vestimenta, naquele cenário, naquele veículo de comunicação, em relação ao gênero em uso e frente a um público específico. Além disso, a linguagem corporal assume um importante papel no radioblog, pois também contribui no efeito de sentido que se quer produzir em uma dada situação de comunicação.

Como tarefa em um trabalho como esse que mostramos, o professor poderia desafiar os alunos a produzirm uma entrevista para radioblog. Nesse caso, eles podem se valer das potencialidades da linguagem visual para apresentar, em forma de vídeo ou fotos, o prato que essa receita visa apresentar, no caso, um prato típico alemão "Eierschmier" e até, por meio da programação computacional, apresentar a receita por escrito ou de forma animada junto ao vídeo gravado. Elementos visuais poderiam ser acrescentados ao cenário como caixinhas de som, CDs, o nome da rádio entre tantas outras possibilidades.

Terminamos o artigo desafiando professores de línguas a, primeiramente, identificar os usos que os alunos fazem da multimodalidade e de outras estratégias digitais no seu cotidiano para, em seguida, planejar o ensino de forma que as 
habilidades dos alunos sejam reconhecidas e continuem se desenvolvendo. Além disso, desafiamos os professores a estudar as potencialidades das linguagens sonora, oral e visual na produção de locuções para rádio, a reconhecer essas linguagens como componentes do texto e compreender o ato de escrever como a capacidade de produzir textos multimodais. Seu trabalho, portanto, pode partir da identificação dos usos da multimodalidade em textos pertencentes a diferentes gêneros digitais ou impressos para, em seguida, propor atividades e momentos de reflexão sobre a composição de textos da atualidade, possibilitando que seus alunos aperfeiçoem os usos da multimodalidade e pensem em novas estratégias multimodais.

\title{
NOTAS
}

\footnotetext{
${ }^{1}$ Mestranda do Curso de Linguística Aplicada, da UNISINOS. Formada em Letras Português/Alemão pela UNISINOS e pelo IFPLA. Professora de Língua Alemã.

${ }^{2}$ Professora do Programa de Pós-Graduação em Linguística Aplicada da Unisinos.

${ }^{3}$ http://www.rotaromantica.com.br/pt-BR, acesso em 20.02.2013.

${ }^{4}$ Eles estavam acostumados a serem filmados semanalmente. A aula em que fizeram a apresentação aconteceu num dia em que não fomos à escola.
}

\section{USES AND CHALLENGES OF MULTIMODALITY IN LANGUAGE TEACHING}

\begin{abstract}
Different ways of producing meaning through writing and reading undergo changes throughout time due to the emergence of new text compositional elements, as well as new forms of organizing and exposing texts, which, in turn, broaden the concept of text and writing. With the increasing access to technology, when students arrive at school they already display some knowledge of multimodality when challenged to produce written texts. In this article, the use of multimodality by $5^{\text {th }}$ graders of a public school located in a small town of Rio Grande do Sul's country side is discussed. It is also shown the need for teachers to be prepared to receive these clients and to provide them with activities that develop their skills, since it is the school's role to teach students how to read and produce a variety of text genres. The different uses children make of multimodality make us reflect on what it means to read and produce texts in the present time.
\end{abstract}

Keywords: Multimodality. Genre. Text production. Language teaching. 


\section{REFERÊNCIAS}

CAFIERO, Delaine. Leitura como processo: caderno do professor. Belo Horizonte: Ceale/FaF/UFMG, 2005.

COSCARELLI, Carla. Hipertextos na teoria e na prática.Belo Horizonte: Autêntica, 2012.

D'ANDREA, C. F. Auto-organização e processo editoriais na Wikipédia: uma análise à luz de Michel Debrun. In.: RIBEIRO, A. E. Leitura e escrita em movimento. São Paulo: Peirópolis, 2010.

DONDIS, Donis A. Sintaxe da linguagem visual. Trad. Jefferson Luiz Camargo. São Paulo: Martins Fontes, 2007.

FLUSSER, Vilém. O mundo codificado: por uma filosofia da comunicação. São Paulo: Cosac Naif, 2007.

GOMES, Luiz Fernando. Hipertexto no cotidiano escolar. São Paulo: Cortez, 2011.

KRESS, Gunther. Visual and verbal modes of representation in electronically mediated communication: the potentials of new forms of text. In: SNYDER, I. Taking literacy into the electronic era. Sydney: Allen \& Unwin, 1998.

. Gains and losses: new forms of texts, knowledge, and learning. Computers and Compositions, v. 22, n. 1, 2004. Disponível em: <http://www.sciencedirect.com>. Acesso em: 23 jun. 2013.

LEMKE, Jay L. Travels in hypermodality. Visual Communication, out. 2002.

Lévy, Pierre. As tecnologias da inteligência: o futuro do pensamento na era da informática. Trad. Carlos Irineu da Costa. Rio de Janeiro: 34, 1993.

MARCUSCHI, L. A.; XAVIER, A. C. Hipertexto e gêneros digitais: novas formas de construção do sentido. Rio de Janeiro: Lucerna, 2005.

ROJO, Roxane; MOURA, Eduardo. Multiletramentos na escola. São Paulo: Parábola Editorial, 2011.

WELLS, G. Dialogic inquiry as collaborative action research. In: NOFFKE, S.; SOMEKH, B. (Ed.). The handbook of educational action research. Thousand Oaks/London: Sage, 2007.

\section{Seminário}

ARAÚJJO, Júlio. Ampliando links com os letramentos visuais: a criação de histórias em quadrinhos. Integrante da mesa-redonda. Letramentos digitais, visuais e outros links - Simpósio Hipertexto 2012. Disponível em:

<http://www.youtube.com/watch?v=u7hEZNOXxHg>. Acesso em: 26 jun. 2013. 